\title{
$\mathrm{CCD}$ 폭 측정 시스템 및 퍼지 PID를 이용한 CFWC 제어기 설계
}

\section{CFWC Scheme for Width Control using CCD Measurement System and Fuzzy PID Controller in Hot Strip Mills}

\author{
박 철 재* \\ (Cheol Jae Park ${ }^{1}$ ) \\ ${ }^{1}$ School of Mechanical and Automotive Engineering, Daegu University
}

\begin{abstract}
In this paper, we propose a CFWC (CCD and fuzzy PID based width control) scheme to obtain the desired delivery width margin of a vertical rolling mill in hot strip process. A WMS(width measurement system) is composed of two line scan cameras, an edge detection algorithm, a glitch filter, and so on. A dynamic model of the mill is derived from a gauge meter equation in order to design the fuzzy PID controller. The controller is a self-learning structure to select the PID gains from the error and error rate of the width margin. The effectiveness of the proposed CFWC is verified from simulation results under a width disturbance of the entry in the mill. Using a field test, we show that the performance of the width control is improved by the proposed control scheme.
\end{abstract}

Keywords: hot strip mills, vertical rolling mill, CCD camera, dynamic model, fuzzy PID, width margin control, roughing mill, edge detection, edger control

\section{I. 서론}

최근 강판의 압연에 있어서 최신 기술들이 개발되어 생 산성이나 치수, 형상 등과 같은 품질이 크게 향상되었고 제 조 가능한 범위도 확대되었다. 열간압연에서의 품질 제어도 강판의 길이 방향으로 두께와 폭을 균일하게 제어하는 치 수제어에서 평탄도, 판 크라운 제어 및 평면 형상제어까지 확대되었다[1,2].

열간압연에서 강판의 폭은 그림 1 에서 보는 것과 같이 제품 폭, 강판 내의 폭 마진 평균(mean of width margin), 강 판 간의 폭 마진 평균의 편차로 관리한다. 강판 내의 폭 마 진을 설정하는 이유는 압연에서 장력이나 압연 조건 등의 변동으로 폭 불량(width shrinkage)이 발생할 가능성이 있기 때문이다. 보통 열간압연에서는 폭 마진을 $7 \mathrm{~mm}$ 정도로 설 정하고 있으며, 고객은 마진을 절단(trim)하고 사용하므로 폭 마진이 클수록 생산량은 떨어진다[3].

열간압연에서 강판의 폭은 조압연(roughing mill), F0 압 연, 마무리 압연(finishing mill) 순서로 압연된다. 폭 측정 시스템(WMS: Width Measurement System)은 조압연 출측, 마무리 압연 출측에 각각 설치되어 있다. 조압연에서는 목 표 폭 마진을 제어하기 위하여 AWC (Automatic Width Control)가 설치되어 피드포워드 $\mathrm{AWC}$, 피드백 $\mathrm{AWC}$, 압연 하중을 이용한 폭 제어(roll force AWC) 등의 제어가 실시

\footnotetext{
* 책임저자(Corresponding Author)

Manuscript received August 20, 2013 / revised September 15, 2013 / accepted October 4, 2013

박철재: 대구대학교 기계자동차공학부(cjpark@daegu.ac.kr)

※ 이 논문은 2011학년도 대구대학교 학술연구비지원에 의한 논 문임.
}

된다. F0 압연은 강판의 폭 압연을 위한 수직 압연기인 F0 엣저(edger), 두께 압연을 위한 수평 압연기로 나눌 수 있 다. 일반적으로 마무리 압연 공정에서의 폭 변동은 조압연 에 비해서 무시할 수 있기 때문에 마무리 압연의 입측 폭 과 제품 폭이 같다고 가정한다. 이와 같은 가정으로 F0 압 연기에서 수평압연 시 폭 퍼짐량을 예측하여 폭 변동이 없 도록 F0 엣저에서 폭을 압연한다[4]. 그러나 F0 압연기의 폭 퍼짐량을 정확하게 예측하기 어렵다. 이는 롤 갭과 압연 하중을 설정하는 모델이 외란의 영향을 많이 받고, 모델에 서 고려할 수 없는 인자들이 너무 많기 때문이다. 더욱 중 요한 이유는 F0 압연기의 출측 폭을 측정하는 계측기가 없 기 때문에 마무리 압연 입측의 폭도 알 수 없다. 따라서 F0 압연 공정에서 정확한 폭을 측정할 수 있는 $\mathrm{WMS}$ 는 열간 압연의 폭 마진을 제어하는데 반드시 필요하다고 할 수 있 다. 열간압연에서 $\mathrm{WMS}$ 는 $\mathrm{CCD}$ 카메라가 많이 사용된다. $\mathrm{F} 0$ 압연에서 $\mathrm{CCD}$ 카메라를 이용할 때 중요한 것은 제철소

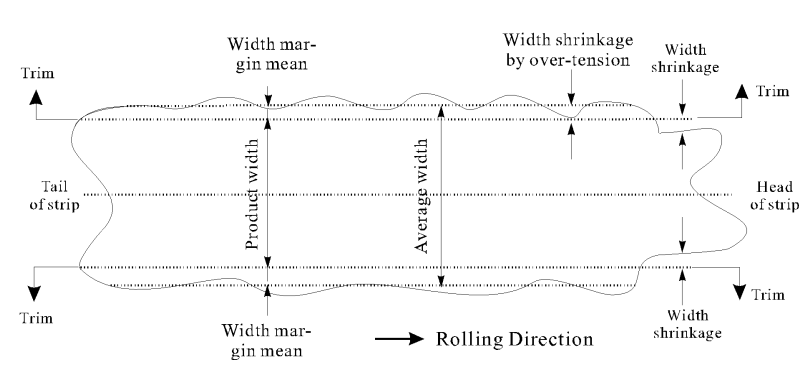

그림 1. 열간 마무리 압연 후의 강판의 평면도.

Fig. 1. Plan view of hot strip after finishing mill. 
의 환경과 에지 검출이다. 압연 공정에서의 수증기, 냉각수, 진동 등의 주위 환경은 에지를 검출하는데 잡음으로 작용 할 수 있으므로 적절한 필터링이 필요하다.

열간압연에서 폭 마진을 제어하기 위한 연구는 조압연과 마무리 압연에서 진행되고 있다. 조압연에서는 $\mathrm{RSU}$ (Roughing Mill Setup)에 의하여 정확한 롤 갭, 압연하중, 온 도를 예측할 수 있는 모델을 개발하고 있다[5-8]. 기본적인 접근은 힘의 평형 조건으로부터 상미분 방정식을 재료의 항복조건식과 계면의 마찰조건을 연립해서 특정한 경계조 건을 이용하여 수치 계산하여 모델의 정도를 높이고 있다. 조압연에서 강판의 길이 방향으로 폭을 제어하는 방법으로 는 폭 예측 모델을 이용하는 피드포워드 $\mathrm{AWC}$, 조압연 출 측의 WMS를 이용하는 피드백 $\mathrm{AWC}$ 가 있다 $[9,10]$. 또한 조 압연의 스키드 마크에 의한 강판의 가공경화가 온도 외란 으로 작용하는 문제를 해결하기 위한 제어도 진행되고 있 다[11]. 마무리 압연에서 폭은 주로 압연 스탠드 간의 루퍼 (looper)에 의한 장력을 이용하여 간접적으로 제어된다 [12-14]. 종래에는 루퍼 각도에 의하여 장력을 제어하는 방 법이었으나 최근에는 루퍼 각도와 장력을 독립적으로 제어 하는 비간섭 제어가 주로 실시된다. 또한 루퍼에 작용하는 토크 모델의 정도를 향상시켜서 모델 예측제어(MPC), ILQ, $\mathrm{CDM}$ 등의 제어 방법이 적용되고 있다[15-17]. 그러나 기존 의 연구들은 다음과 같은 문제점이 있다. 첫째, 기존에는 조압연과 마무리 압연 각각의 공정에서 폭을 제어하기 때 문에 조압연에서 폭이 변동하더라도 마무리 압연에서는 그 영향을 고려할 수 없었다. 둘째, 마무리 압연 입측에 폭 측 정 시스템의 부재로 입측 폭에 대한 정확한 정보를 알 수 없어서 폭 모델의 정도에만 의존한다는 문제점이 있다.

본 논문에서 수행한 연구 내용은 크게 두 가지로 대별된 다. 첫째, 마무리 압연 입측 폭의 정확한 정보를 알기 위하 여 $\mathrm{CCD}$ 를 이용하는 폭 측정 시스템을 개발한다. 이를 위하 여 열간압연 공정의 폭 측정 신호의 필터링 방법과 에지를 검출하는 방법에 대하여 서술한다. 둘째, $\mathrm{CCD}$ 를 이용하여 측정된 마무리 압연 입측 폭과 조압연 출측 폭을 이용하여 퍼지 PID 제어기를 개발하여 F0 엣저의 폭 제어 알고리즘 (CFWC: CCD and fuzzy PID based width control)을 개발하 는 것이다. 개발된 제어 알고리즘을 바탕으로 시뮬레이터를 개발하고 시뮬레이션 결과를 바탕으로 열간압연 공장에서 온라인으로 테스트하여 알고리즘의 정당성을 분석한다.

이 논문의 구성은 다음과 같다. II 장에서는 제어대상 프 로세스에 대하여 설명하고 폭 제어의 문제점들을 서술한다. III 장에서는 $\mathrm{CCD}$ 폭 측정 시스템과 필터링 방법 및 에지 검출 방법에 대하여 서술한다. IV 장에서는 퍼지 PID 제어 기를 이용한 $\mathrm{CFWC}$ 제어 모델을 도출하고 제어기를 설계 한다. $\mathrm{V}$ 장에서는 개발된 $\mathrm{CFWC}$ 제어기를 현장과 같은 조 건에서 시뮬레이션하고, 그 결과를 바탕으로 실시한 온라인 테스트 결과를 분석한다. 이 논문의 결론은 VI 장에서 요약 한다.

\section{II. 제어대상 프로세스와 폭 제어 문제}

1. 제어대상 프로세스

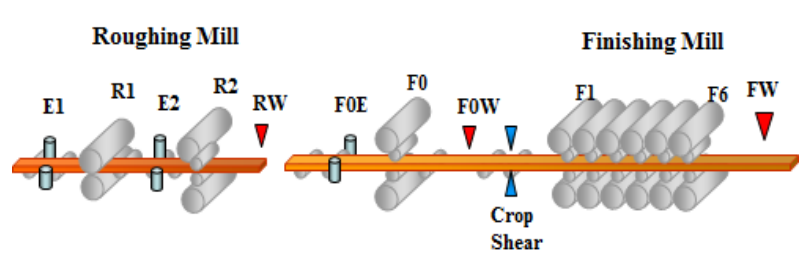

그림 2. 열간압연 조압연, $\mathrm{F} 0$ 및 마무리 압연.

Fig. 2. Roughing, $\mathrm{F} 0$ and finishing mill of hot strip mills.

그림 2는 제어대상 프로세스인 열간압연 공정을 나타낸 다. 열간압연 공정은 크게 조압연과 F0 압연 및 마무리 압 연으로 나눌 수 있다. 조압연에서는 주로 강판의 폭을 압연 하여 일정한 폭으로 생산할 수 있도록 하며, 2 개의 수직 압 연기(E1, E2)와 2개의 수평 압연기(R1, R2)로 구성되어 있 다. 수직 압연기에는 압연 하중을 이용하여 폭을 제어하기 위한 압연 하중 $\mathrm{AWC}$ 및 조압연 출측 폭계(RW)를 이용한 피드백 $\mathrm{AWC}$ 로 구성된다. 수평 압연기에서는 폭 퍼짐이 있 으며 이를 예측하기 위한 폭 퍼짐 예측모델에 대한 연구가 진행되고 있다[5].

F0 압연은 마무리 압연 입측에서 폭을 수직 압연하기 위 한 F0 엣저(F0E: F0 edger)와 길이 방향으로 압연하기 위한 수평 압연기(F0 압연기)가 있다. F0 압연에서는 주로 마무 리 압연기와의 장력 제어를 통하여 압연 강판의 직진성을 양호하게 하여 안정적인 압연이 가능하도록 한다. 그림에서 $\mathrm{F} 0 \mathrm{~W}(\mathrm{~F} 0 \mathrm{WMS}$ )는 본 연구에서 개발한 WMS가 설치된 위치 이며 마무리 압연기의 입측에 설치되어 정확한 폭 제어를 가능하게 한다.

마무리 압연기는 보통 6 7개의 압연기로 구성되며 정밀 한 제품을 생산하기 위한 두께, 폭 및 형상제어기가 설치되 어 있다. 압연기 간에 설치된 루퍼는 강판의 높이 및 장력 을 제어하며 강판의 직진성을 좋게하고 압연에 의한 강판 의 버퍼링 역할을 담당한다. 마무리 압연기의 출측에는 $\mathrm{FW}$ (F6 WMS)라고 하는 WMS가 설치되어 있다.

\section{2. 기존 폭 제어의 문제점}

기존의 공정에서는 RSU에서 RW 목표 폭, FSU (Finishing Mill Setup)에서 FW 목표 폭을 각각 설정한다. 그러나 조압 연에서 $\mathrm{AWC}$ 를 이용하여 $\mathrm{RW}$ 를 정밀하게 제어한다 하더라 도 F0 압연기에서 수직 및 수평 압연에 의해 강판이 압연 될 때 정밀 제어가 되지 않으면 제품 폭은 불량이 될 수도 있다. 이는 기존의 공정에서는 F0W가 설치되어 있지 않아 그림 2의 $\mathrm{FOW}$ 를 정확하게 측정하기 어렵기 때문이다.

그림 3은 기존의 폭 제어에 의한 폭 마진 불량 데이터를 나타낸다. 그림의 점선은 $\mathrm{RW}$ 폭 마진, 실선은 $\mathrm{FW}$ 폭 마진 을 각각 나타낸다. 조압연은 강판의 길이가 약 $10 \mathrm{~m}$ 이고, 마무리 압연은 약 $1 \mathrm{~km}$ 이기 때문에 데이터의 개수가 차이 가 있다. 그림에서 조압연 폭 마진의 평균과 표준편차는 각 각 $18 \mathrm{~mm}, 0.84 \mathrm{~mm}$ 이고, 마무리 압연의 경우에는 $16 \mathrm{~mm}$, $1.3 \mathrm{~mm}$ 이다. 즉, 강판의 길이 방향으로 조압연 출측에서는 $0.84 \mathrm{~mm}$ 의 편차로 폭 제어가 실시되어 마진이 양호하였으나 마무리 압연 입측에서는 정확한 폭 마진을 알 수 없다. 이 로 인하여 마무리 압연에서 폭 마진 편차가 $1.3 \mathrm{~mm}$ 로 약 


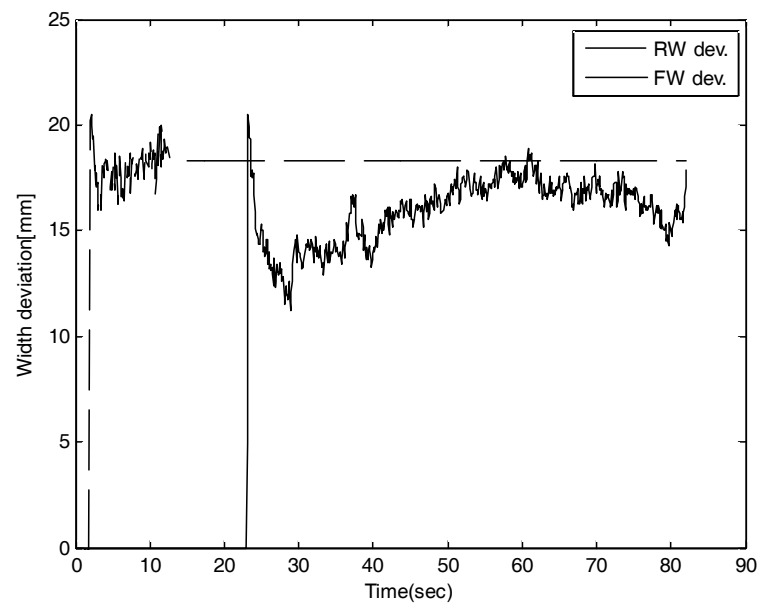

그림 3. 기존의 폭 제어에 의한 폭 마진 불량.

Fig. 3. Problem of width margin by conventional control.

$35.3 \%$ 정도 폭 마진 편차가 증가하였으며, 이로 인하여 생 산성이 크게 떨어지는 문제가 발생한다.

이상과 같은 문제점으로부터 마무리 압연에서 강판의 폭 제어를 위해서는 마무리 압연 입측의 폭 제어가 중요하며 이를 위한 WMS 및 제어 방법의 개발이 필요하다는 것을 알 수 있다.

\section{CCD 폭 측정 시스템 개발}

1. WMS 개요

본 연구에서는 열악한 환경에서 연속적으로 강판의 폭을 측정하도록 $\mathrm{CCD}$ 스테레오 $\mathrm{WMS}$ 를 개발하였다. 측정 가능 한 강판의 폭 정밀도는 $\pm 0.5 \mathrm{~mm}$, 최대 측정 폭은 $2400 \mathrm{~mm}$ 이 며 실시간으로 온라인 측정한다. 강판의 영상은 고정도 렌 즈와 필터를 구비한 두 개의 $\mathrm{CCD}$ 를 통해 획득하며 각각의 $\mathrm{CCD}$ 는 강판의 폭 방향으로 라인 스캔된 파형을 출력한다. 이러한 파형으로부터 엣지 추출 알고리즘을 통해 강판의

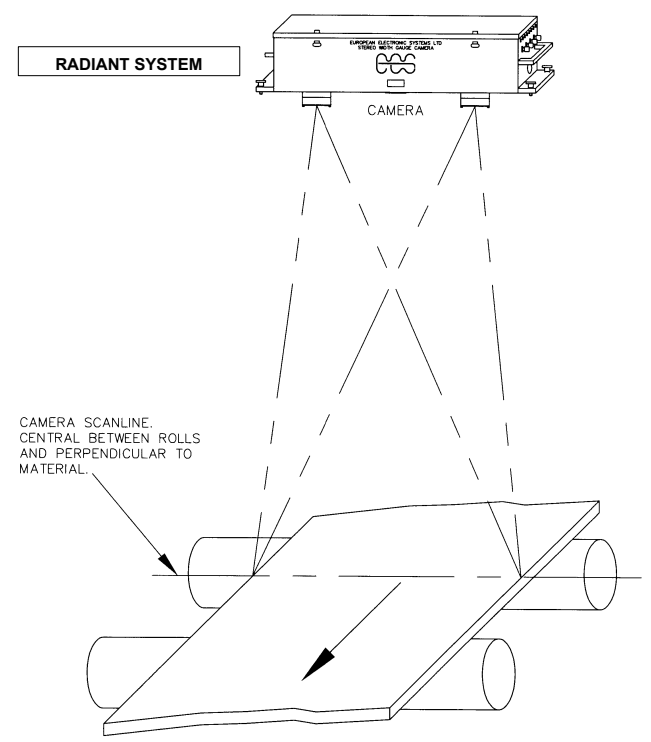

그림 4. $\mathrm{CCD}$ 카메라 어셈블리 위치.

Fig. 4. Position of camera assembly for CCD.
좌측 엣지와 우측 엣지의 위치를 추출한다. 그림 4는 카메 라 어셈블리와 강판을 나타내고 있다.

본 카메라의 프로세서 캐비닛은 WMS의 제어와 모니터 링을 위해 설치하였으며, 제어와 모니터링 판넬, 프로세서 카드 랙, 서킷 브레이크 판넬, 외부 통신 판넬 등으로 구성 되어 있다.

$\mathrm{WMS}$ 는 옵티컬 베드(optical bed), 카메라 전자장치, 카메 라 전원, 내부 냉각판 등으로 구성되어 있다. 옵티컬 베드 는 Delsa에서 제조한 두 개의 $\mathrm{CCD}$ 라인 스캔 카메라로 구 성되어 있다. 각각은 2048 개의 어레이를 가지고 있으며 각 어레이는 $4 \mathrm{MHz}$ 의 8 비트 디지털 데이터를 생성한다. 각각의 라인 스캔 카메라는 옵티컬 베드에 정확하게 정렬, 보정되 어 장착되며 베드 내의 온도 측정을 위한 센서도 별도로 부착되어 있다. 카메라 전자장치는 Delsa 카메라 유닛과 캐 비닛간의 인터페이스를 수행하는 카메라 인터페이스 $\mathrm{PCB}$ 를 포함한다. 카메라 인터페이스 $\mathrm{PCB}$ 는 카메라 데이터 신 호, 제어 신호 및 파워 신호를 조작한다.

2. 엣지 추출 알고리즘

강판으로부터 입력된 영상은 밝기에 따라 $\mathrm{CCD}$ 카메라에 의해 1 바이트의 빛의 강도 정보(light intensity)로 변환되며, 이는 0-255의 범위를 갖게 된다. 또한 $\mathrm{CCD}$ 카메라는 0-2047의 총 2048개의 픽셀을 가지고 있다.

강판의 좌측 또는 우측 엣지의 정확한 위치를 추출하기 위해 강도 정보 값의 최대 변화량을 가지는 부분을 엣지로 인식한다(그림 5). 강판의 자발광으로부터 엣지를 추출하는 열간 압연의 경우 좌측 엣지의 강도 변화량은 양의 값을 가 지며, 우측 엣지의 강도 변화량은 음의 값을 가지게 된다.

엣지 추출 프로세스가 시작되면 관심영역(AOI: Area Of Interest)의 추출을 시작한다. 관심영역은 파라미터 설정 화 면으로부터 설정된 스레스홀드 값(threshold factor of AOI) 에 의해 추출된다. 이렇게 추출된 $\mathrm{AOI}$ 의 교차점(AOI crossing)은 정확한 엣지 추출을 위한 출발점이 된다. 다음 으로 $\mathrm{AOI}$ 의 교차점으로부터 옵셋 영역(AOI to edge offset)

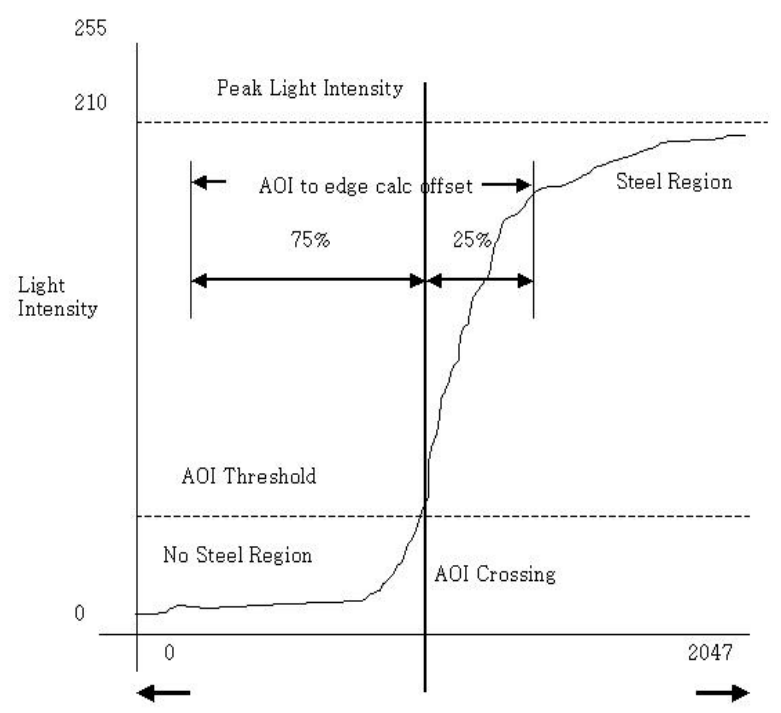

그림 5. 엣지 추출 알고리즘.

Fig. 5. Algorithm of edge detection in WMS. 


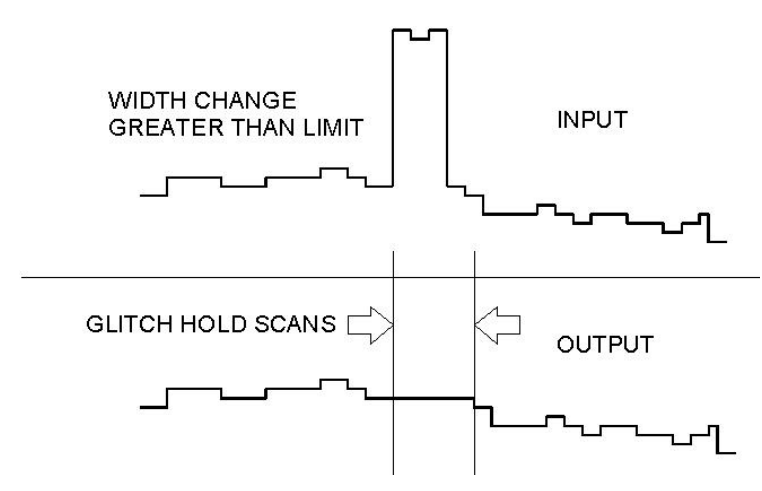

그림 6. Glitch 필터의 노이즈 보상.

Fig. 6. Compensation of noise for glitch filter.

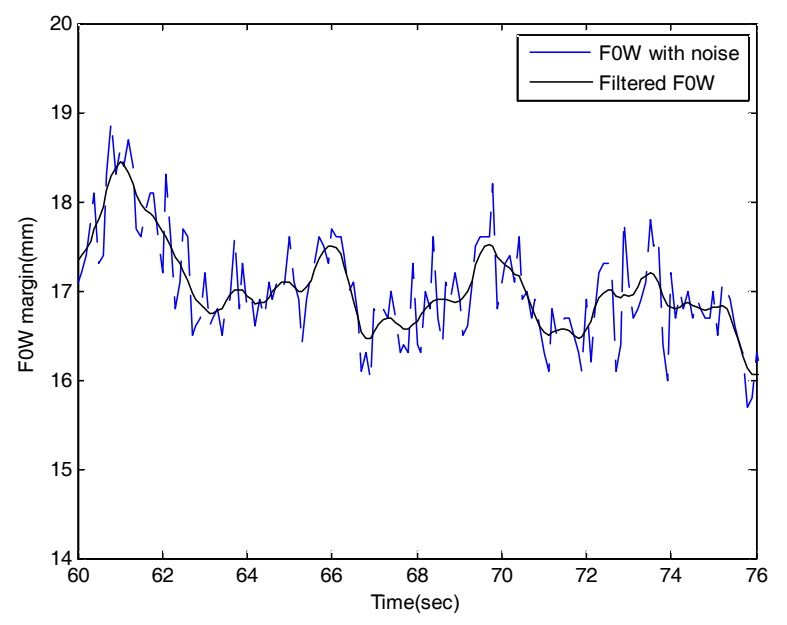

그림 7. Glitch 필터의 필터링 결과.

Fig. 7. Result of fitering using glitch filter.

만큼 이동된 픽셀의 위치에 대해 밝기 값의 변화율을 얻는 다. 이러한 변화율은 $\Delta X$ 로 설정된 픽셀 거리에 대해 밝기 값의 차이로 결정되며 옵셋 영역 전체에 대해 $\Delta X$ 만큼 이동시켜 가며 각 픽셀에 대한 변화율을 구한 후 가장 큰 변화율 값을 가진 픽셀을 엣지점으로 판단한다.

\section{3. 폭 측정 신호의 필터링}

열간 압연에서 폭 측정 시 센서 자체의 노이즈와 주변 환경의 불균일성 등의 영향이 크기 때문에 이로부터 잘못 된 정보를 얻을 수 있다. 따라서 강판 폭과 중심 위치 계산 을 위하여 본 연구에서는 glitch 필터를 설계하였다[18]. Glitch의 방법은 크게 이전 데이터와 비교하는 방법과 이전 데이터들의 평균과 비교하는 방법의 두 가지로 구분할 수 있으며 glitch의 크기, 최대 크기 등의 파라미터를 사전에 설정할 수 있다. 그림 6과 7은 glitch 필터의 노이즈 보상방 법과 필터링 결과를 각각 나타내었다.

\section{IV. 퍼지 PID 폭 제어기 설계}

1. 수직 압연기(FOE)의 모델링

마무리 압연의 입측에서 폭 제어기를 설계하기 위하여 $\mathrm{FOE}$ 압연기를 모델링한다. $\mathrm{F} 0 \mathrm{E}$ 압연기의 폭과 롤 갭은 다음 과 같은 게이지미터(gaugemeter) 식으로 나타낼 수 있다[10].

$$
W=S+\frac{P}{K_{m}}
$$

여기서 $W$ 는 $\mathrm{F0E}$ 압연기 출측 폭, $S$ 는 압연기의 롤 갭 (gap), $P$ 는 압연 하중, $K_{m}$ 은 압연기 강성(stiffness) 이다. 압 연 하중은 롤 반경 $(R), \mathrm{FOE}$ 압연기의 입측 폭 $\left(W_{0}\right)$ 및 출측 폭 $(W)$, 마찰계수 $(\mu)$, 변형저항 $\left(a_{1}\right)$ 등의 함수이며 다음과 같 이 나타낼 수 있다.

$$
P=f\left(R, W_{0}, W, \mu, a_{1}\right)
$$

열간압연의 동특성으로부터 F0E 압연기를 모델링하기 위 하여 게이지미터 식 (1)의 미소 변동량을 고려한다.

$$
\delta W=\delta S+\frac{\delta P}{K_{m}}
$$

압연 하중 (2)의 미소 변동은 다음과 같이 된다[19].

$$
\begin{aligned}
\delta P & =\left(\frac{\partial P}{\partial R}\right) \delta R+\left(\frac{\partial P}{\partial W_{0}}\right) \delta W_{0}+\left(\frac{\partial P}{\partial W}\right) \delta W \\
& +\left(\frac{\partial P}{\partial \mu}\right) \delta \mu+\left(\frac{\partial P}{\partial a_{1}}\right) \delta a_{1}
\end{aligned}
$$

(4)를 (3)에 대입하면 다음과 같이 $\mathrm{FOE}$ 압연기의 동특성을 나타내는 동적 모델링을 얻을 수 있다.

$$
\begin{aligned}
v_{s} \delta S+v_{R}\left(\frac{\delta R}{R}\right) & +v_{W_{0}}\left(\frac{\delta W_{0}}{W_{0}}\right) \\
& +v_{\mu}\left(\frac{\delta \mu}{\mu}\right)+v_{a_{1}}\left(\frac{\delta a_{1}}{a_{1}}\right)+v_{W}\left(\frac{\delta W}{W}\right)=0
\end{aligned}
$$

여기서

$$
\begin{aligned}
& v_{s}=\frac{K_{m}}{K_{m}-\left(\frac{\partial P}{\partial W}\right)} \frac{1}{W}, v_{\lambda}=\frac{1}{K_{m}-\left(\frac{\partial P}{\partial W}\right)} \frac{\lambda}{W}\left(\frac{\partial P}{\partial \lambda}\right) \\
& v_{W}=-1,
\end{aligned}
$$

이고 $\lambda$ 는 $R, W_{0}, \mu, a_{1}$ 등을 나타낸다.

2. 퍼지 PID 제어기 설계

퍼지 PID 제어기는 PID 제어 게인들을 퍼지 자기학습 (self-learning) 방법으로 구한다. PID 제어기의 구조는 다음 과 같다.

$$
u_{P I D}(t)=K_{p}\left[e(t)+\frac{1}{T_{i}} \int_{0}^{t} e(t) d t+T_{d} \frac{d e(t)}{d t}\right]
$$

$\mathrm{PID}$ 제어 게인들은 파라미터 $\alpha$ 를 도입하여 다음과 같이 나타낼 수 있다[20].

$$
\begin{aligned}
& K_{p}=5 \alpha+k_{u} \\
& T_{i}=0.75 \frac{1}{1+|\alpha|} t_{u}, \quad T_{d}=0.25 T_{i}
\end{aligned}
$$

여기서 $k_{u}, t_{u}$ 는 각각 임계 게인, 임계 주기이다.

그림 8은 퍼지 PID 제어기의 구조를 나타낸다. RSU로부 터의 폭 마진 설정값 $\left(w_{r e f, f 0 E}\right)$ 의 오차 $e(t)$ 와 오차의 시간 변화율 $d e(t)$ 로부터 $\mathrm{PID}$ 제어 게인들을 자기학습하며 $\mathrm{F0E}$ 


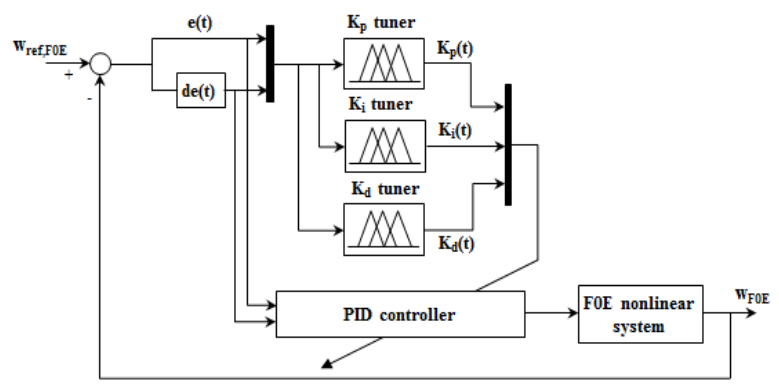

그림 8. 퍼지 PID 제어기의 구조.

Fig. 8. Structure of fuzzy PID controller.

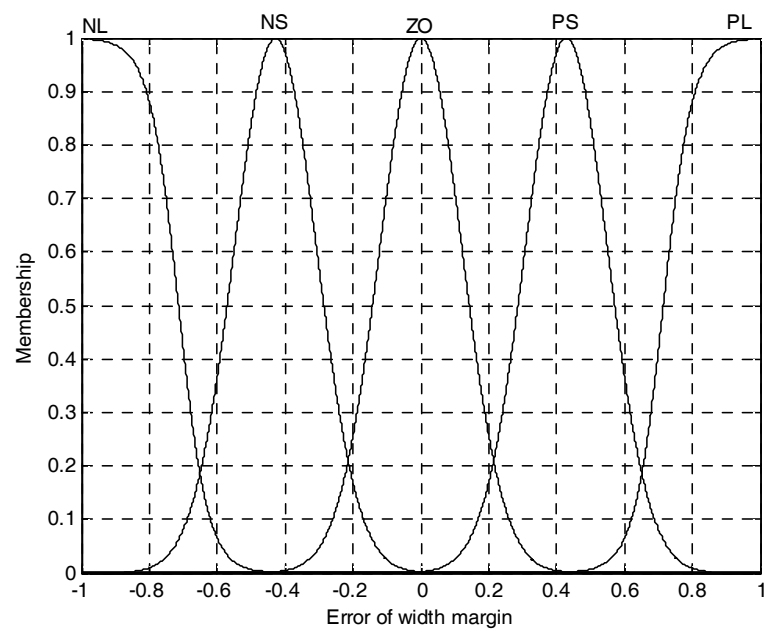

그림 9. 폭 마진 오차의 멤버쉽 함수.

Fig. 9. Membership function of width margin error.

동적 모델로 입력되는 구조이다.

제어기를 설계하기 위하여 $e(t)$ 와 $d e(t)$ 를 각각 퍼지 변수인 $\mathrm{E}$ 와 $\mathrm{R}$ 로 퍼지화하며 다음과 같이 5 개의 퍼지 집합 으로 나타낼 수 있다.

$$
\begin{aligned}
& \mathrm{E}=\{\mathrm{NL}, \mathrm{NS}, \mathrm{ZO}, \mathrm{PS}, \mathrm{PL}\} \\
& \mathrm{R}=\{\mathrm{NL}, \mathrm{NS}, \mathrm{ZO}, \mathrm{PS}, \mathrm{PL}\}
\end{aligned}
$$

여기서 NL은 negative large, NS는 negative small, ZO는 zero, PS는 positive small, PL은 positive large를 각각 나타낸 다. 그림 9는 $e(t)$ 에 대한 퍼지 멤버쉽 함수를 나타낸다. $e(t)$ 의 입력은 $-1 \sim 1, d e(t)$ 는 -0.2 0.2의 값을 가지며 가우 시안 멤버쉽 함수의 형태이다.

퍼지 변수 $\mathrm{E}$ 와 $\mathrm{R}$ 로부터 출력의 퍼지 변수 $\mathrm{H}$ 로 사상 (mapping) 하기 위한 퍼지 규칙은 삼각형 형태의 멤버쉽 함 수를 사용한다. 여기서 $\mathrm{H}$ 는 -1 1의 퍼지 집합으로 구성된다.

퍼지 변수 $\mathrm{H}$ 로부터 비퍼지화의 기법인 무게 중심법을 사용하여 $h(t)$ 를 구한다. $h(t)$ 가 구해지면 (7)식의 $\alpha$ 는 다음 과 같은 회귀식으로부터 구할 수 있다.

$$
\alpha(t+1)=\kappa \cdot \alpha(t)+\lambda \cdot h(t)
$$

여기서 $\kappa$ 와 $\lambda$ 는 양의 상수이며 1 보다 작은 값으로 적절히 선정된다.

그림 10 은 $\mathrm{CCD} \mathrm{WMS}$ 와 퍼지 $\mathrm{PID}$ 제어기로 구성된 폭

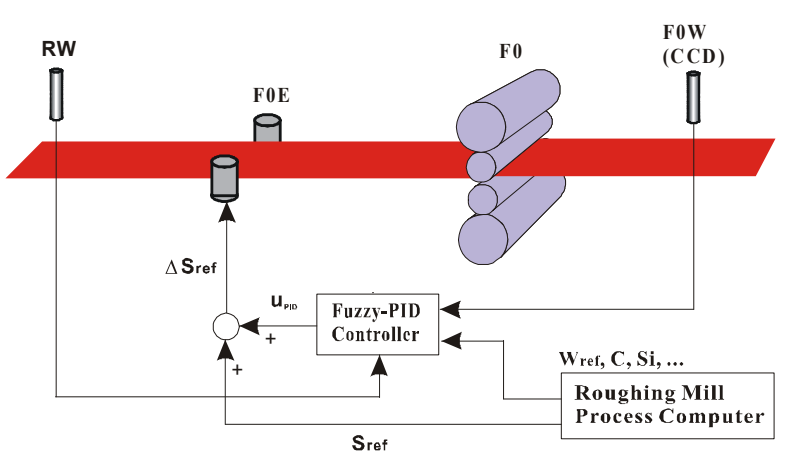

그림 10. $\mathrm{F} 0 \mathrm{E}$ 압연기의 폭 제어 시스템의 구조.

Fig. 10. Structure of width control system in F0E rolling mill.

제어 시스템을 나타낸다. 폭 제어기는 조압연 프로세스 컴 퓨터에서 폭 설정값 $\left(\mathrm{W}_{\mathrm{ref}}\right)$ 및 탄소 $(\mathrm{C})$, 실리콘 $(\mathrm{Si})$ 함유량 등 의 정보를 입력 받고, $\mathrm{FOW}, \mathrm{RW}$ 등의 실적치를 수집한다. 그리고 (6)과 같이 계산된 제어 입력(UPID)을 이용하여 FOE 압연기의 롤 갭을 제어함으로써 폭을 정밀하게 제어할 수 있다.

\section{V. 시뮬레이션 및 온라인 테스트}

1. 퍼지 PID 제어기의 시뮬레이션

본 장에서는 컴퓨터 시뮬레이션을 통하여 앞에서 설명한 제어기의 알고리즘을 검증하고 결과를 고찰한다. 표 1 은 시 뮬레이션에 사용된 주요 압연 조건을 나타낸다.

$\mathrm{F} 0 \mathrm{E}$ 압연기의 입측 폭의 변동은 다음과 같이 외란 $(d)$ 으 로 정의한다.

$$
d=d_{1}+A_{1} \sin 2 \pi f_{1}(t)+A_{2} \sin 2 \pi f_{2}(t)
$$

여기서 $d_{1}$ 은 계단(step) 입력으로써 계단입력 시간은 $1 \mathrm{sec}$, 폭 변동량은 $1 \mathrm{~mm}$ 이다. 그리고 사인형태의 외란을 생성하 기 위하여 $A_{1}=0.1 \mathrm{~mm}, A_{2}=0.05 \mathrm{~mm}, f_{1}=0.2 \mathrm{~Hz}, f_{2}=1 \mathrm{~Hz}$ 를 각각 인가하였다.

그림 11은 입측 폭 외란, 기존의 PID 제어기와 제안한 퍼지 PID 제어기에 대한 폭 마진의 시간 응답을 나타내었 다. PID 제어기는 외란의 영향을 충분히 제거할 수 없는 구조이기 때문에 외란의 진폭과 주기를 크게 줄이지 못하 는 것으로 나타났다. 퍼지 PID 제어기는 $e(t)$ 와 $d e(t)$ 의 변화에 대하여 정상상태 오차와 오버슈트가 거의 없이 바 람직한 제어 응답을 나타내었다. 본 논문에서는 Mamdani의 퍼지 추론 방법(fuzzy inference method) [21]을 사용하여 제 어기의 성능을 향상시켰다.

그림 12 는 두 제어기의 제어 입력을 나타내었다. PID 제 어기의 제어 입력은 작게 계산되어 외란을 줄이기 어렵다.

표 1. 퍼지 PID 알고리즘 검증을 위한 시뮬레이션 조건.

Table 1. Simulation conditions for fuzzy PID control algorithm.

\begin{tabular}{|c|c|c|c|}
\hline Parameter & Value & Parameter & Value \\
\hline 조압연 폭 $(\mathrm{mm})$ & 1,330 & 압연하중 $(\mathrm{ton})$ & 55 \\
\hline 제품 폭 $(\mathrm{mm})$ & 1,300 & 롤 직경 $(\mathrm{mm})$ & 1,080 \\
\hline 롤 속도 $(\mathrm{mpm})$ & 68 & 밀 강성 $(\mathrm{ton} / \mathrm{mm})$ & 100 \\
\hline
\end{tabular}




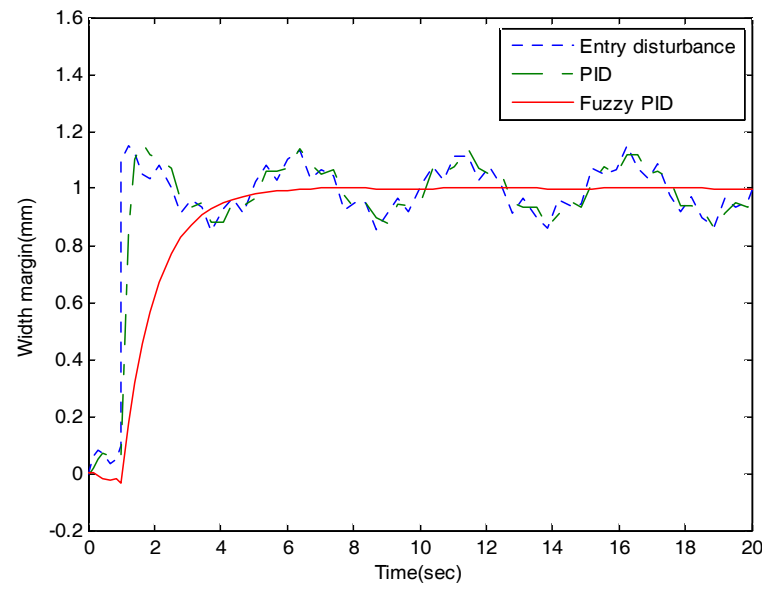

그림 11. 제안한 제어기의 폭 마진 시간 응답.

Fig. 11. Time response of width margin for proposed controller.

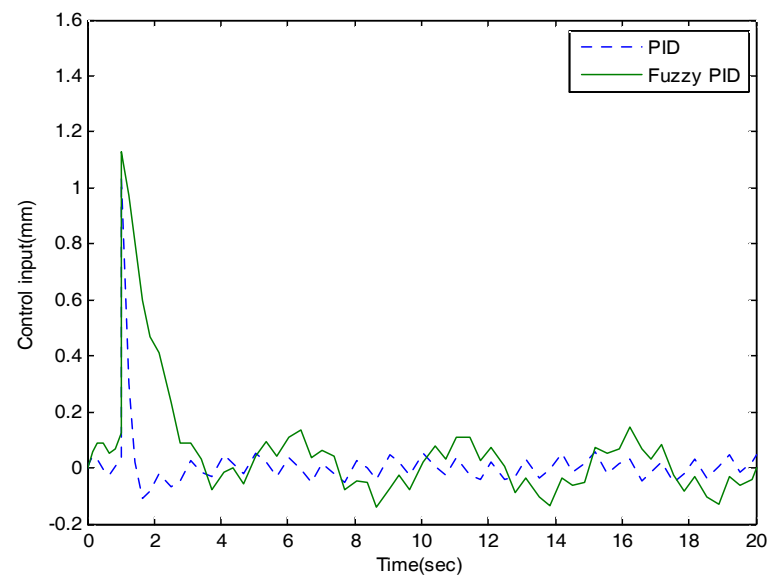

그림 12. 제어 입력의 시간 응답.

Fig. 12. Time response of control input for proposed controller.

퍼지 PID 제어기의 입력 $e(t)$ 는 폭 마진 오차를 크게 줄여 서 0 이 되는 방향으로 제어되고 있음을 알 수 있다. 그림에 서 PID 제어기의 입력 평균과 편차는 각각 $0.001 \mathrm{~mm}, 0.033$ $\mathrm{mm}$ 이며, 퍼지 $\mathrm{PID}$ 제어기는 각각 $0.99 \mathrm{~mm}, 0.078 \mathrm{~mm}$ 로써 제안된 제어기의 입력이 크게 작용하고 있음을 알 수 있다.

2. 온라인 테스트 결과

그림 13 은 개발된 $\mathrm{CFWC}$ 시스템을 열연 공장에서 온라 인으로 테스트한 결과를 나타내었다. 그림의 점선은 F0 압 연기의 출측에서 $\mathrm{CCD} \mathrm{WMS}$ 로 측정한 폭 마진이고 실선은 마무리 압연 출측에서 측정한 폭 마진이다. $\mathrm{RSU}, \mathrm{FSU}$ 에서 출력된 $\mathrm{FOW}, \mathrm{FW}$ 의 목표 폭은 각각 $10 \mathrm{~mm}, 7 \mathrm{~mm}$ 이다. 약 $10 \mathrm{sec}$ 에 FoW의 마진이 목표 폭보다 작기 때문에 퍼지 PID 제어가 시작된다. 그러나 실제로 폭 제어의 효과가 나타나 는 시점은 그림에서 보는 것과 같이 폭 마진이 증가하기 시 작하는 약 $19 \mathrm{sec}$ 이다. 이것은 $\mathrm{F} 0 \mathrm{~W}$ 의 $\mathrm{WMS}$ 와 $\mathrm{F} 0 \mathrm{E}$ 사이의 거리(약 $7 \mathrm{~m})$ 에 의한 측정지연과 $\mathrm{FOE}$ 의 롤 갭을 제어하는 액츄에이터의 응답지연 때문이다. 폭 마진 데이터는 식 (10) 과 같이 저주파에 해당되며, 이와 같은 측정지연과 응답지 연이 제어에 미치는 영향은 향후 많은 연구가 필요하다.

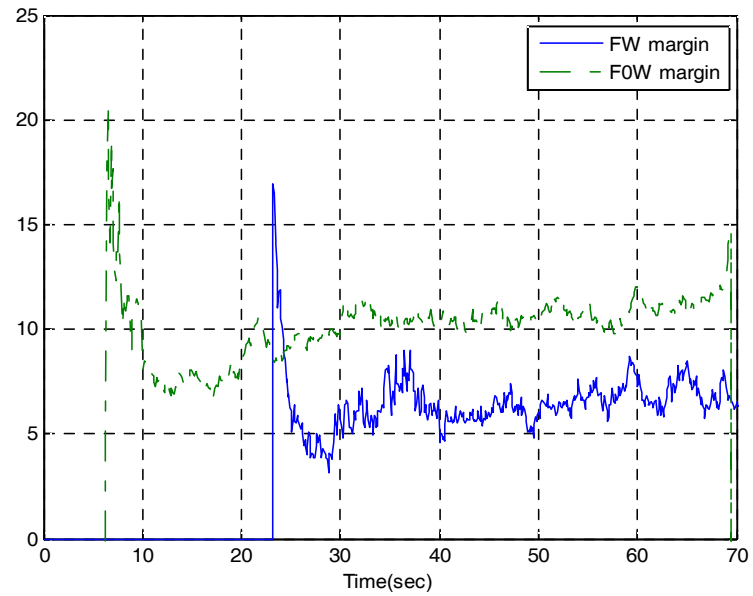

그림 13. CFWC 시스템의 온라인 테스트 결과.

Fig. 13. Test result of CFWC system.

온라인 테스트 결과 $\mathrm{FOW}$ 폭 마진의 평균과 표준편차는 각각 $9.95 \mathrm{~mm}, 0.7 \mathrm{~mm}, \mathrm{FW}$ 폭 마진의 경우는 각각 $6.97 \mathrm{~mm}$, $0.5 \mathrm{~mm}$ 로써 목표 폭 마진으로 수렴하였다. 이는 그림 3 의 종전의 테스트 결과보다 평균은 $44.7 \%(18 \rightarrow 9.95)$, 표준편차 는 $16.7 \%(0.84 \rightarrow 0.7)$ 정도 향상된 것을 알 수 있다.

\section{VI. 결론}

본 논문에서는 열간압연 공정에서 마무리 압연기의 입측 폭 마진을 제어하기 위하여 $\mathrm{CCD}$ 를 이용하는 $\mathrm{WMS}$ 를 개발 하고, 퍼지 PID 제어기에 근거한 $\mathrm{CFWC}$ 제어기를 설계하였 고 시뮬레이션을 통해 알고리즘을 검증하고, 열연 공장에 온라인으로 테스트 하였다.

개발된 $\mathrm{WMS}$ 는 자발광 타입의 두 개의 라인 스캔 카메 라로 구성된 옵티컬 베드를 사용하였고 관심영역에서의 스 레스홀드 값을 설정하여 엣지를 추출하였다. 폭 측정 시의 노이즈 등을 제거하기 위하여 glitch 필터를 설계하였다.

퍼지 PID 제어기를 설계하기 위하여 수직 압연기의 동특 성을 게이지미터 식으로부터 유도하였다. 제어기는 폭 마진 설정값의 오차와 오차의 시간 변화율로부터 PID 제어 게인 을 선정하는 자기학습 구조이다.

제안한 CFWC 제어기에 대한 현장 테스트 결과, F0W 폭 마진의 평균과 편차는 각각 $44.7 \%, 16.7 \%$ 감소하여 치수제 어의 정도가 크게 향상된 것을 확인할 수 있었다.

\section{REFERENCES}

[1] K. Yamada, S. Ogawa, and M. Ataka, "Three dimensional analysis at rolling using rigid-plastic finite element method coupled with roll deformation analysis," NUMIFORM 92, pp. 755-760, 1992.

[2] T. Sasaki, "Mathematical model of width change in the hot strip finishing train," CAMP-ISIJ, vol. 9, pp. 304-307, 1996.

[3] T. Shibahara, "Edger set-up model at roughing train in hot strip mill," ISIJ, vol. 67, no. 15, pp. 2509-2515, 1981. 
[4] X. Z. Du, Q. Yang, C. Lu, A. L. Wang, and T. A. Kiet, "Optimization of short stroke control preset for automatic width control of hot rolling mill," Journal of Iron and Steel Research, vol. 17, no. 6, pp. 16-20, 2010.

[5] A. Hacquin and P. Montmitonnet, "Coupling of roll and strip deformation in three-dimensional simulation of hot rolling," Simulation of Mat. Proc., pp. 921-927, 1995.

[6] A. Helmi and J. Alexander, "Geometric factors affecting spread in hot at rolling of steel," JISI, no. 206, pp. 1110-1117, 1968.

[7] A. Ishii, "Variation of strip width during hot finishing rolling," CAMP-ISIJ, vol. 9, pp. 300-303, 1996.

[8] J. Price, "The hot strip mill looper system," IEEE Transactions on Industry Applications, vol. IA-9, no. 5, pp. 556-562, 1973.

[9] X. L. Zang, X. T. Li, and F. S. Du, "Head and tail shape control in vertical-horizontal rolling process by FEM," Journal of Iron and Steel Research, vol. 16, no. 5, pp. 35-42, 2009.

[10] C. J. Park and I. C. Hwang, "Width control systems with roll force automatic width control and finishing vertical mill automatic width control in hot strip mill," Journal of Materials Processing Technology, vol. 206, no. 1-3, pp. 143-151, 2008.

[11] S. Nakamura, M. Takahashi, and Y. Chida, "Slab width control for hot direct rolling," Transactions of the Iron and Steel Institute of Japan, vol. 28, pp. 110-116, 1988.

[12] S. Murata, "Development of width control technology in finishing line of hot strip mill," CAMP-ISIJ, vol. 9, pp. 308-311, 1996.

[13] H. Yoneda, "Development of accurate width control technology in hot strip finishing mill," CAMP-ISIJ, vol. 9, pp. 312-315, 1996.

[14] T. Ogura, "Advanced width control for hot finishing mill," CAMP-ISIJ, vol. 9, p. 324, 1996.

[15] S. Kunimatsu, T. Fujii, and T. Tsujino, "Quadratic stabilization of ILQ servo systems with generalized reference inputs," T. SICE, vol. 39, no. 3, pp. 307-309, 2003.

[16] H. Imanari, Y. Morimatsu, K. Sekiguchi, H. Ezure, R. Matuoka, A. Tokuda, and H. Otobe, "Looper H-Infinity control for hot strip mills," IEEE Transactions on Industry Applications, vol. 33, no. 3, pp. 790-796, 1997.

[17] C. J. Park and I. C. Hwang, "New tension control at the head of strip in hot strip finishing mill," Journal of Materials Processing Technology, vol. 206, no. 1-3, pp. 69-77, 2008.

[18] W. C. Tsai, C. B, Shung, and D. C. Wang, "Accurate logic-level power simulation using glitch filtering and estimation," IEEE Asia Pacific Conference on Digital
Object Identifier, pp. 314-317, 1996.

[19] G. M. Liu, H. S. Di, C. L. Zhou, H. C. Li, and J. Liu, "Tension and thickness control strategy analysis of two stands reversible cold rolling mill," Journal of Iron and Steel Research, vol. 19, no. 10, pp. 20-25, 2012.

[20] S. Z. He, S. Tan, F. L. Xu, and P. Z. Wang, "Fuzzy self-tuning of PID controller," Fuzzy Sets and Systems, vol. 56, no. 1, pp. 37-46, 1993.

[21] E. Hennebach and W. Dilger, "Algebraic operations on a class of Mamdani-controllers," Fuzzy Sets and Systems, vol. 101, no. 2, pp. 253-259, 1999.

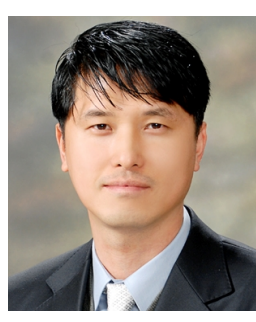

박 철 재

1992년 부산대학교 정밀기계공학과 졸 업(공학사). 1994년 동 대학원 졸업(공 학석사). 2008년 서울대학교 전기컴퓨 터공학부 졸업(공학박사). 1994년 2008 년 포스코 기술연구소 근무. 2008년 9 월 현재 대구대학교 기계자동차공학부 교수. 관심분야는 모델예측제어, 견실제어, 프로세스 규명 및 제어, 메카트로닉스 등. 